\title{
The effect of firm's logo on its performance: Evidence from oil industry
}

\author{
Jafar Jafari $\mathbf{i}^{*}$
}

${ }^{a}$ MA in Marketing, Department of Management, Central Branch, Islamic Azad University, Tehran, Iran

\begin{tabular}{|c|c|}
\hline CHRON I C LE & A B S T RACT \\
\hline $\begin{array}{l}\text { Article history: } \\
\text { Received January 5, } 2016 \\
\text { Received in revised format June } \\
15,2016 \\
\text { Accepted July 21, } 2016 \\
\text { Available online } \\
\text { July 25, 2016 } \\
\text { Keywords: } \\
\text { Logo } \\
\text { Company's Performance } \\
\text { Likeness/Description Benefits } \\
\text { Benefits } \\
\text { Functional Benefits } \\
\text { Aesthetic Tendencies }\end{array}$ & $\begin{array}{l}\text { Nowadays, trade mark is one of the most important components of the products in both } \\
\text { consumers and producers' perspectives. In this study, two separate but related mechanism } \\
\text { through which the trademark is supposed to create value for customers, were investigated. } \\
\text { Likeness/ description and functional-aesthetic benefits were taken into consideration. This } \\
\text { research shows the positive effects of logo on customer commitment regarding the performance. } \\
\text { Commitment reflects customers' desire for cooperation by considering the effects of a logo. } \\
\text { Logo will help customers easily identify and select a brand. This research proves that, from the } \\
\text { customer's perspective, trademarks contain meaning, and thus include brief information on the } \\
\text { struggle for marketing. In case of the purpose, this study is an applied research and in terms of } \\
\text { data-gathering it is a descriptive - survey one. Since the population of the survey was unlimited, } \\
\text { initial investigations indicated that } 384 \text { questionnaires should be distributed based on Morgan } \\
\text { table. Using structural equation modeling, the survey results showed that descriptive-cognitive, } \\
\text { functional benefits and aesthetic tendencies had significant influences on customer commitment } \\
\text { in regards of performance. }\end{array}$ \\
\hline
\end{tabular}

\section{Introduction}

A good brand will add benefit and value to goods and generates some advantageous for consumers and consumers will also adhere to names which create value for them. According to Kotler, (2009) brand can be defined as "a name, term, sign, symbol or combination of them intended to identify a product or service to a seller or a group of sellers and distinguishes the goods or services from that of a competitor". A brand is an important medium to create a positive image in customer's minds, which results in difference with available products (Kotler, 2009). Trademarks resolve the lack of recognition by the clients. It is essential to note that the positive image of the brand with the marketing efforts of the firm is not eternal and the emergence of more new products with attractive logos will affect it. As mentioned, customers are able to establish a significant relationship with a brand logo. Brand is an intangible asset which has considerable influence on performance (Woo et al., 2008). 
For example, the ancient Chinese used symbol of the dragon to express imperial power. In addition to be a means of distinguishing, logo helps to convey meanings and information about the product or service. Good logos can result in a good reputation and form positive customers' attitudes, their goal of purchasing and loyalty. In fact, previous studies about branding suggest that logos work as a visual display of the original meaning of the brand and public image. Logos could affect the economic value of a company (Walsh et al., 2010).

Oliver (1999) defines loyalty as a strong commitment to repurchase a product or a premier service in the future and referring to the same product or brand, despite the impact of competitors and their marketing efforts for selling products (Rahimi Helari \& Hosseini, 2012). This research proves that in customers' view, logo represents its meaning and therefore it is a brief information on the struggle for marketing. The reason for the importance of the topic is that brands have the ability to provide cognitive explanations, and logos are important tools for communication between the brand and the people. Due to increasing car productions and machineries, and consequently production of needed oil derivatives, there exists a gap of research regarding logos of these products to identify their benefits and performance. We hope that this research will be fruitful in the respective industry.

Müller et al. (2013) studied the brand revitalization by investigating the impacts of logo similarity and type of logo on brand modernity and brand loyalty and highlighted the importance of certain logo characteristics in describing logo attitude and presenting the effects on brand modernity, brand attitude, and finally, brand loyalty.

Shukla (2011) studied how interpersonal influences and branding cues could shape consumer luxury purchase intentions based on a sample of British and Indian consumers. He reported that normative interpersonal influences were significant across nations but the role of informational interpersonal effects was significant only among Indian consumers. He also reported that British consumers depended increasingly on branding cues, brand image was a significant moderator between normative interpersonal influences and luxury purchase intentions in both countries.

\section{Literature Review}

\subsection{Concepts and theories}

Brand bears a connotation more than a product or a service. Nowadays, many goods and services, especially in petrochemical and oil and its derivatives, are not different significantly and it is the brand that makes the basic distinctions. The resulting image of the brand, its performance advantages and descriptive-cognitive benefits, come from brand logo and can be effective on customer commitment and performance of the bank. Therefore, this paper conducts a survey in respect of the different kinds of logos and their effects; those who have used mere signals for logos and those who used just names or a combination of the two. Building a positive attitude of a bank logo can affect consumer attitudes and identity and should be kept in mind that a positive attitude appears from a good experience of a product. Brand awareness benefits include a descriptive-cognitive benefits, functional benefits and brand image. As awareness of the brand and its relationship with customers' perception of quality increases, it starts to increase customer loyalty which promotes the performance.

\subsubsection{Likeness / descriptive Benefits}

Brand has the ability to help us describe the definition of the concerned consumer. It will differentiate the customers from others, for instance, a brand may represent various parts of the identity of customers; such as core beliefs/values or a life cycle which they believe in (Van den Bosch et al., 2005). Also, logos connect people to each other who share similar values and beliefs. 
Since logos represent trademarks, they could potentially be the source of connections for customers through strengthening the brand's core values. In other words; a trademark logo is an essential tool for communication between brands and people which, in turn, help customers feel the sense of belonging. Besides, since logos build a form for trademark, they enhance their credibility and tend to incite customers. Logos have the potential to express their communications and empower them. Hence, the customers' desire for more efforts and investment to continue their relationships with the trade show will be increased (Thomson et al., 2005). Engendering a symbolic relationship with a brand is essential, but there would be a stronger affinity with the trademark that fostered relationships with customers.

\subsubsection{Functional benefits}

The researchers suggest that the brand can be managed to reduce uncertainty in people's lives and enable them to facilitate the efficient control in obtaining the desired results. Therefore, the brand may have an effective sense to help people perform their daily activities well. Logos are visual display of a trademark which reminds functional advantage to customers. For instance, consider Red Bull logo that two opposing striker bull with the sun shining in front of the brand ensures that this product gives life to the mind and body. Customers are normally familiar with companies, which could meet their requirements because they make their life easier and they will not shift to competitor companies as long as they are happy with the service they receive. This study aims at logos with functional benefits which encourage customers to compensate and being dependent to the respective trademark. As a result, trademark has the potential to empower commitment among customers. In this way, logos strength the relations with customers (Walsh et al., 2010).

\subsubsection{Aesthetic tendencies}

Throughout history, beauty and design trends have been of human interest and imagination have taken them in their hands. Handicrafts and admiring objects with attractive shapes have a long history. Thus, previous researches on logo emphasized on aesthetic aspects. In addition to visual delight, aesthetic tendencies in logo can foster emotional bond with customers. Trademarks with aesthetic attraction facilitates communication with customers. For instance, the Walt Disney Company's brand logo with an image of a fairy castle may contain a substantial effect on customers. Similarly, Hello Kitty with a funny image of a white kitty fosters a deep relationship with clients around the world based on the funny design. Therefore, aesthetic tendency is the key factor which exhibits the power of a firm to form mutual relationship with potential customers and will result in customer loyalty (Woo et al., 2008).

\subsection{Theoretical framework}

Brand bears a connotation more than a product or a service. Nowadays, many goods and services, especially in petrochemical and oil and their derivatives, are not different significantly and it is the brand that makes the basic distinctions. The resulting image of the brand, its performance advantages and descriptive-cognitive benefits, come from brand logo and can be effective on customer commitment and performance of the bank. Creating a positive attitude of a bank logo can influence consumer attitudes and identity and should be kept in mind that a positive attitude comes from a good experience of a product. Brand awareness benefits include a descriptive-cognitive benefits, functional benefits and brand image (Park et al., 2013).

\subsection{Conceptual Research Model}

Initial conceptual model based on the research accomplished by Park et al. (2013) is given by Fig. 1 as follows: 


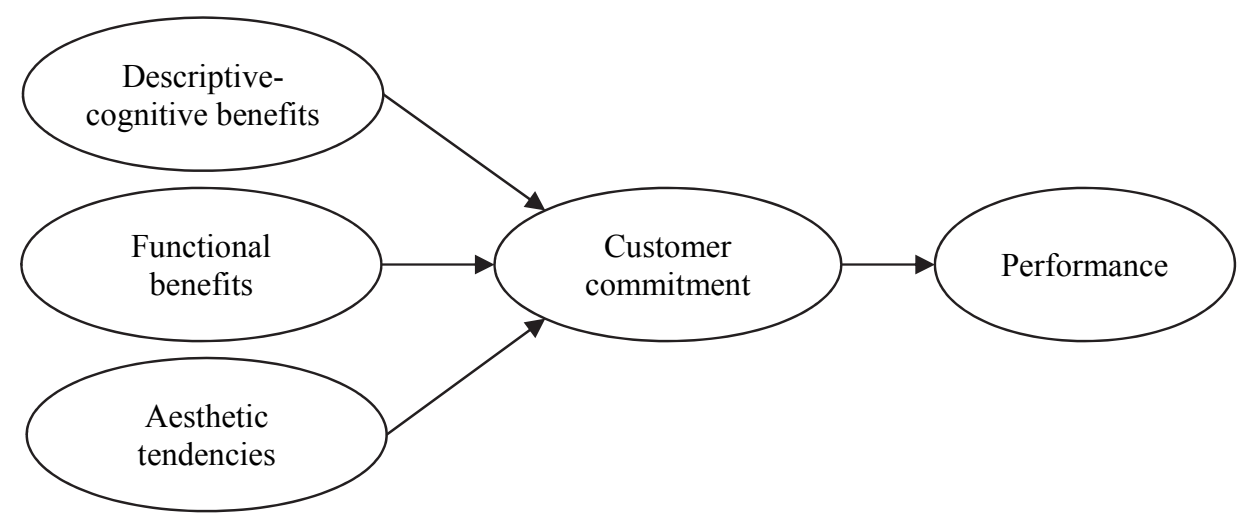

Fig. 1. Conceptual model of the research based on the study accomplished by Park et al. (2013)

\subsection{Research Hypotheses}

Based on the conceptual model, the researchers' hypotheses are:

1. Descriptive-cognitive benefits of a logo on customer commitment are impressive.

2. The functional benefits of a brand logo on customer commitment are impressive.

3. Aesthetic tendencies of a brand logo influence customer commitment.

4. Customer commitment influences the oil companies' performance.

\section{Methodology}

The present study is considered functional according to the fact that the results of it can be applied by managers and officials of oil companies. Regarding data collection, the study is a descriptive - survey one, also it can be categorized as cross-sectional survey type as well. Survey method is a way to obtain information on attitudes, beliefs, opinions and behaviors of members of population through study. We call it a cross-sectional study as it is a type of observational study that involves the analysis of data collected from a population, or a representative subset, at one specific point in time. The population of this study includes all Sepahan Oil Company's customers in Tehran. Due to some limitations such as time and budget limitation and distribution of customers and consumers of petroleum products in all parts of Tehran, sampling was implemented. Due to the fact that the population size is not specified, 384 cases were chosen based on Kerjesy and Morgan table. Sampling method was simple random.

In order to collect necessary information for the study, the following methods were used:

- Books, articles and Persian and English websites,

- Data associated with similar researches

In this study, questionnaire was used to collect field data. In this section, 16 questions were raised to assess the effectiveness of contextual factors and criteria related to Sepahan Oil Company's logo. In order to check the validity of the questionnaire, professors' opinions were taken into consideration. Also, Cronbach's alpha was used to assess the reliability of the results. Following is the result.

\section{Table 1}

Reliability by Internal Consistency Method (Cronbach's alpha)

\begin{tabular}{lcc}
\hline Variables & Number of Questions & Cronbach's alpha \\
\hline Cognitive-descriptive benefits & 3 & 0.72 \\
Functional benefits & 3 & 0.84 \\
Aesthetic tendencies & 3 & 0.74 \\
Customer commitment & 3 & 0.73 \\
Performance & 4 & 0.82 \\
\hline
\end{tabular}


SPSS 22 and LISREL 9.1 software were used for data analysis.

\section{Findings}

\subsection{Normality test of basic variables}

In order to confirm the normality of data, Skewness and Kurtosis tests have been applied to determine the distribution of the data. The results of the tests show that the research's variables were normally distributed. Skewness and Kurtosis values of all variables were within the range of \pm 1 . The Skewness of cognitive-descriptive benefits variable is -0.231 , functional benefits is -0.320 , aesthetic tendencies is 0.415 , customer commitment equals to 0.309 and performance variable is 0.309 . Also, Kurtosis values of all variables are between +1 to -1 , which indicates that the distributions of the basic variables were not significantly deviant from the normal distribution. So, variables' distribution may be rendered as normal or near to normal.

\section{Table 2}

Skewness and kurtosis values to assess the normality of variables

\begin{tabular}{lcc}
\hline Variable & Skewness & Kurtosis \\
\hline Cognitive-descriptive benefits & -0.231 & -0.303 \\
Functional benefits & -0.320 & -0.294 \\
Aesthetic tendencies & 0.415 & 0.474 \\
Customer commitment & 0.309 & -0.312 \\
Performance & -0.449 & -0.585 \\
\hline
\end{tabular}

\subsection{Correlation of variables}

The results show that all relationships among variables were approved $(\mathrm{P}<0.05)$. There exists a positive relationship between variables of cognitive-descriptive benefits and functional benefits $(r=0.25)$. There exists a positive relationship between variables of cognitive-descriptive benefits and aesthetic tendencies $(\mathrm{r}=0.24)$, a positive relationship between variables of cognitive-descriptive benefits and customer commitment $(\mathrm{r}=0.39)$, a positive link between performance relationship and cognitivedescriptive benefits $(r=0.27)$, a positive relationship between functional benefits and aesthetic tendencies $(\mathrm{r}=0.12)$, a positive relationship between functional benefits and customer commitment $(\mathrm{r}$ $=0.55)$, a positive link between functional benefits and performance relationship $(\mathrm{r}=0.37)$, a positive relationship between aesthetic tendencies and customer commitment $(\mathrm{r}=0.33)$, a positive relationship between aesthetic tendencies and performance relationship $(\mathrm{r}=0.11)$, a positive relationship between customer commitment and performance $(\mathrm{r}=0.43)$. The strongest relationship between was between the functional benefits and customer commitment with the correlation of 0.55 .

\section{Table 3}

Correlation matrix of variables

\begin{tabular}{|c|c|c|c|c|c|}
\hline Variable & & & & & \\
\hline Cognitive-descriptive benefits & - & & & & \\
\hline Functional benefits & $0.25^{* *}$ & - & & & \\
\hline Aesthetic tendencies & $0.24^{* *}$ & $0.12^{*}$ & - & & \\
\hline Customer commitment & $0.39^{* *}$ & $0.55^{* *}$ & $0.33^{* *}$ & - & \\
\hline Performance & $0.27^{* *}$ & $0.37^{* *}$ & $0.11^{* *}$ & $0.43^{* *}$ & - \\
\hline
\end{tabular}

** Correlation at a significance level of less than 0.01

* Correlation significant at the level of less than 0.05 


\subsection{SEM}

Fig. 2 and Fig. 3 shows the model in standard coefficients and t-values, respectively. As we can observe, most coefficients are meaningful when the level of significance is one percent.

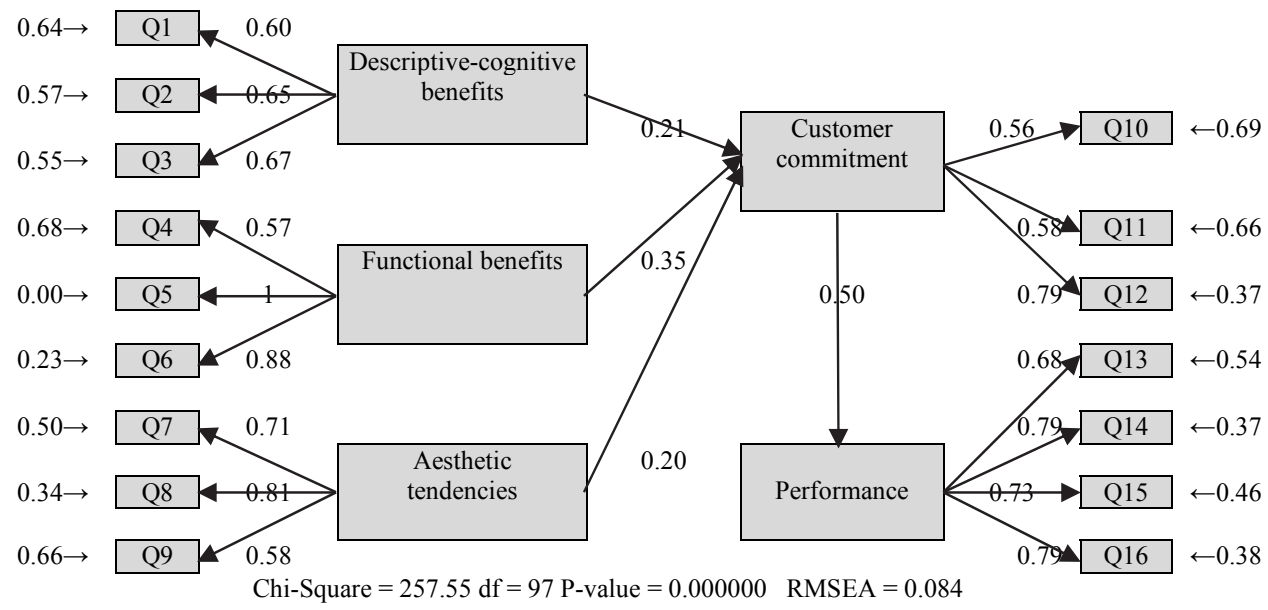

Fig. 2. The results of standard coefficients

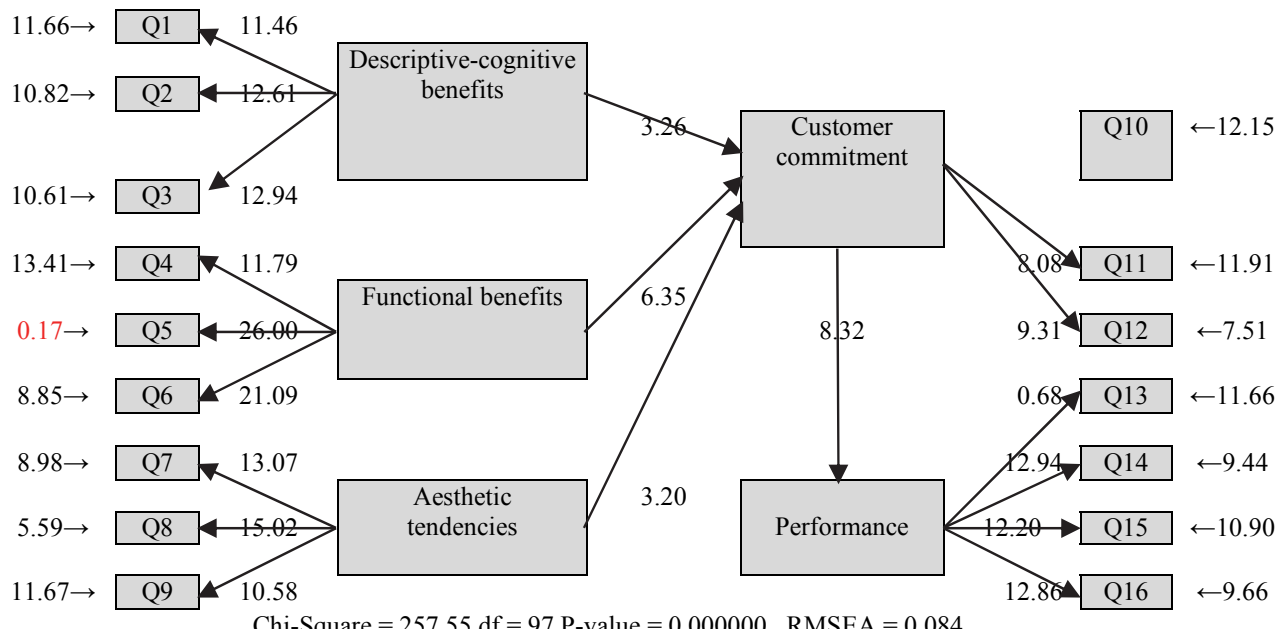

Fig. 3. The results of t-values

Fitted model indexes are listed in the Table 4 and by assessing all fitted indexes, it may be concluded that all achieved fitted indexes were acceptable and data were appropriately fitted to the model.

\section{Table 4}

Model's fitting indexes

\begin{tabular}{ccccc}
\hline Type of index & Indexes & Favorable amount & Result & Analysis \\
\hline \multirow{3}{*}{ Absolute } & Chi-Square & $>0.05 \mathrm{P}$ & $<0.05 \mathrm{P}$ & Lack of good fitting \\
& GFI & $>0.9$ & 0.91 & Well fitted \\
& RMSEA & $<0.08$ & 0.084 & Approximately fitted \\
\hline \multirow{3}{*}{ Relative } & CFI & $>0.9$ & 0.92 & Well fitted \\
& NFI & $>0.9$ & 0.89 & Approximately fitted \\
& IFI & $>0.9$ & 0.9 & Well fitted \\
\hline \multirow{3}{*}{ Concise or thrifty } & AGFI & $>0.5$ & 0.56 & Well fitted \\
& PGFI & $>0.5$ & 0.55 & Well fitted \\
& df Chi-Square & $2 \leq$ index $\leq 3$ & 2.65 & Well fitted \\
\hline
\end{tabular}




\subsection{Research hypotheses test}

Table 5 presents the summary of testing the hypotheses of the survey. As it can be seen, the relationships and conceptual model show that all of the hypotheses have been confirmed.

\section{Table 5}

Research hypothesis test, standard coefficient and significance level

\begin{tabular}{lccr}
\hline Hypothesis & $\begin{array}{c}\text { Standard } \\
\text { coefficient }\end{array}$ & Sig. & Result \\
\hline Effects of cognitive-descriptive benefits of logo on customer commitment & 0.21 & $\mathrm{P}<0.01$ & Confirmed \\
Effects of functional benefits of logo on customer commitment & 0.35 & $\mathrm{P}<0.01$ & Confirmed \\
Effects of aesthetic tendencies of logo on customer commitment & 0.2 & $\mathrm{P}<0.01$ & Confirmed \\
Effects of customer commitment on oil Company & 0.5 & $\mathrm{P}<0.01$ & Confirmed \\
\hline
\end{tabular}

\section{Discussion and conclusion}

\subsection{Discussion}

\section{First hypothesis test}

The results suggest that at confidence level of $99 \%$, cognitive-descriptive benefits of logo have a significant relationship with customer commitment $(\mathrm{P}<0.01)$. The positive standardized coefficient equals to 0.21 . So, the first hypothesis of the research which stated that cognitive-descriptive benefits of logo affect customer commitment, is confirmed at $99 \%$ confidence level.

\section{Second hypothesis test}

The results show a significant relationship between functional benefits of logo and customer commitment $(\mathrm{P}<0.01)$. The results show a direct relationship or positive relationship between these two variables. Standardized coefficient of functional benefits of logo on customer commitment equals to 0.35. Totally, the results suggest that the research's second hypothesis which stated that functional benefits of logo affect customer commitment, is confirmed at $99 \%$ confidence level.

\section{Third hypothesis test}

The results suggest that at confidence level of $99 \%$, aesthetic tendencies of logo have a significant relationship with customer commitment $(\mathrm{P}<0.01)$. The positive standardized coefficient equals to 0.20. So, the third hypothesis of the research which stated that aesthetic tendencies of logo affect customer commitment, is confirmed at $99 \%$ confidence level.

\section{Fourth hypothesis test}

The results show a significant relationship between customer commitment and Oil Company's performance $(\mathrm{P}<0.01)$. The results show a positive relationship. Standardized coefficient equals to 0.50 . Totally, the results suggest that the research's fourth hypothesis which stated that customer commitment affects Oil Company's performance is confirmed at 99\% confidence level.

\subsection{Conclusion}

Within the petroleum and petrochemical industry, having a strong, effective and communicative brand can be a competitive advantage. In other word, it should illustrate the benefits which the respective product brings to the customers and consumers. This study has performed an empirical investigation to study the role of the Sepahan Oil Company's trade show on the performance of the Company. The 
results showed that the managers should always consider their products' trademark from three perspectives of cognitive-descriptive benefits, functional benefits and aesthetic tendencies, and visual sign in a brand logo as an up-to-dated ongoing position. This study determined that managers need to continually review and consider brands as a powerful and influential tool in customer relationship management. A client's rapid detection of a brand logo does not mean that customer spends his/her time and resources to establish and maintain communications with a brand. Visual signs as a brand logo give a good opportunity to repeat presentation. This study found that brands with a logo were performing better than logos which were formed merely by name. According to the conducted research and achieved confirmation for all hypotheses, it is suggested that future studies would focus on factors affect descriptive-cognitive benefits (such as color, font and set of elements associated with a logo) to identify the relationships between and customers' behavior.

\section{Acknowledgement}

The authors would like to thank the anonymous referees for constructive comments on earlier version of this paper.

\section{References}

Kotler, P. (2009). Marketing management: A south Asian perspective. Pearson Education India.

Müller, B., Kocher, B., \& Crettaz, A. (2013). The effects of visual rejuvenation through brand logos. Journal of Business Research, 66(1), 82-88.

Oliver, R. L. (1999). Whence consumer loyalty?. The Journal of Marketing, 63, 33-44.

Park, C. W., Eisingerich, A. B., Pol, G., \& Park, J. W. (2013). The role of brand logos in firm performance. Journal of Business Research, 66(2), 180-187.

Rahimi Helari, M., \& Hosseini, S.M. (2012). Effect of brand equity on consumer response (Case study Iranol Brand). MBA thesis in Shahid Beheshti University.

Shukla, P. (2011). Impact of interpersonal influences, brand origin and brand image on luxury purchase intentions: Measuring interfunctional interactions and a cross-national comparison. Journal of world business, 46(2), 242-252.

Thomson, M., MacInnis, D. J., \& Park, C. W. (2005). The ties that bind: Measuring the strength of customers' emotional attachment to brands. Journal of Consumer Psychology, 15(1), 77-91.

Van den Bosch, A. L. M., de Jong, M. D. T., \& Elving, W. J. L. (2005). How corporate visual identity supports reputation. Corporate Communications, 10(2), 108-116.

Van Riel, C. B. M., \& Van den Ban, A. (2001). The added value of corporate logos. An empirical study. European Journal of Marketing, 35(3/4), 428-440.

Walsh, M. F., Winterich, K. P., \& Mittal, V. (2010). Do logo redesigns help or hurt your brand? The role of brand commitment. The Journal of Product and Brand Management, 19(2), 76-84.

Woo, J. J., Chang-Hoan, C., \& Hyuck Joon, K. (2008). The role of affect and cognition in consumer evaluations of corporate visual identity: Perspectives from the United States and Korea. Journal of Brand Management, 15(6), 382-398.

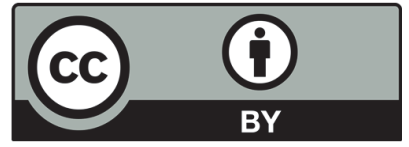

(C) 2016 by the authors; licensee Growing Science, Canada. This is an open access article distributed under the terms and conditions of the Creative Commons Attribution (CC-BY) license (http://creativecommons.org/licenses/by/4.0/). 